\title{
Anterior Bone Loss in Cervical Disc Arthroplasty
}

\author{
David Christopher Kieser, Derek Thomas Cawley, Takashi Fujishiro, Celeste Tavolaro, Simon Mazas, \\ Louis Boissiere, Ibrahim Obeid, Vincent Pointillart, Jean Marc Vital, Olivier Gille
}

L'Institut de la Colonne Vertébrale, CHU Pellegrin, Bordeaux, France

\begin{abstract}
Study Design: Retrospective, longitudinal observational study.
Purpose: To describe the natural history of anterior bone loss (ABL) in cervical disc arthroplasty (CDA) and introduce a classification system for its assessment.

Overview of Literature: ABL has recently been recognized as a complication of CDA, but its cause and clinical effects remain unknown.

Methods: Patients with non-keeled CDA (146) were retrospectively reviewed. X-rays were examined at 6 weeks, 3, 6, 9, 12, 18, and 24 months, and annually thereafter for a minimum of 5 years. These were compared with the initial postoperative $X$-rays to determine the ABL. Visual Analog Scale pain scores were recorded at 3 months and 5 years. Neck Disability Index was recorded at postoperative 5 years. The natural history was determined and a classification system was introduced.

Results: Complete radiological assessment was available for 114 patients with 156 cervical disc replacements (CDRs) and 309 endplates (average age, 45.3 years; minimum, 28 years; maximum, 65 years; $57 \%$ females). ABL occurred in $57.1 \%$ of CDRs (45.5\% mild, $8.3 \%$ moderate, and $3.2 \%$ severe) and commenced within 3 months of the operation and followed a benign course, with improvement in the bone stock after initial bone resorption. There was no relationship between ABL degree and pain or functional outcome, and no implants were revised.

Conclusions: $\mathrm{ABL}$ is common (57.1\%). It occurs at an early stage (within 3 months) and typically follows a non-progressive natural history with stable radiographic features after the first year. Most ABL cases are mild, but severe ABL occurs in approximately $3 \%$ of CDAs. ABL does not affect the patients' clinical outcome or the requirement for revision surgery. Surgeons should thus treat patients undergoing $\mathrm{CDA}$ considering $\mathrm{ABL}$.
\end{abstract}

Keywords: Cervical disc replacement; Disc arthroplasty; Bone loss; Osteolysis; Avascular necrosis

\section{Introduction}

Cervical disc arthroplasty (CDA) was first published in the medical literature by Reitz and Joubert [1] in the South African Medical Journal in 1964. Since its introduction, the use of CDA for treating symptomatic cervical disc pathology has continued to increase. This has been supported by favorable outcomes reported in the literature [26]. Its use has also been facilitated by the theoretical benefit to the adjacent levels with maintained disc motion $[7,8]$. However, an increased use of CDA has identified potential complications $[9,10]$, including those associated with the

Received Jan 8, 2018; Revised May 24, 2018; Accepted Jun 3, 2018

Corresponding author: David Christopher Kieser

Department of Orthopaedic Surgery and Musculoskeletal Medicine, University of Otago, 2 Riccarton Avenue, Christchurch, 8011 New Zealand

Tel: +64-21-149-9829, Fax: +64-3-467-9709, E-mail: kieserdavid@gmail.com 
surgical approach (infections, neurovascular injury, and dysphagia), surgical technique (wrong level surgery, persistent neurological deficit, postoperative kyphosis, migration, and subsidence), and implant (failure, debris, heterotrophic ossification, osteolysis, and dislocation) [9].

Multiple implants are available for use in CDA, including those with various materials, biomechanical philosophies, and constraint degrees. However, all implants aim to maintain motion and thus, like other joint arthroplasties, are prone to bone loss from debris deposition, micromotion, and stress shielding [11-23].

Anterior bone loss (ABL) in CDA has been recognized in ProDisc [24,25], Bryan CDA [22], and Baguera-C CDA implants [26]. In ProDisc, bone loss was observed around its central keel $[24,25]$. In contrast, in Bryan CDA bone loss predominantly affects the superior adjacent vertebra of the operative segment around the anterior flange of the prosthesis [22]. Heo et al. [26] reported on 48 patients treated with Baguera-C CDA and showed that ABL occurred in more than $60 \%$ of the patients.

We hypothesized that $\mathrm{ABL}$ in $\mathrm{CDA}$ is rare and progressive. This study therefore aimed to examine the radiographic sequential progression of $\mathrm{ABL}$ and to understand its natural history to predict the likely etiology and provide surgeons with an understanding of this phenomenon.

\section{Materials and Methods}

We performed a retrospective analysis of longitudinal observations using standardized of antero-posterior (AP), lateral and flexion/extension radiographs of non-keeled CDAs performed within L'Institut de la Colonne Vertébrale, CHU Pellegrin, Bordeaux, France with a minimum 5-year follow-up. The implants included the Bryan disc (Medtronic Sofamor Danek, Memphis, TN, USA; 46 patients), the Discocerv (Alphatech Spine Inc., Carlsbad, CA, USA; 41 patients), and the Baguera C (Spineart, Geneva, Switzerland; 59 patients).

This study was approved by the Institutional Review Board of L'Institut de la Colonne Vertébrale, CHU Pellegrin, Bordeaux, France (IRB approval no., IRB01ABL).

Images were assessed by DK and confirmed by DC. $\mathrm{ABL}$ was recorded as the percentage AP subchondral vertebral body length, referenced from the posterior vertebral body line, at follow-up compared with that in the immediate postoperative lateral X-ray (Fig. 1).

Implant uncoverage was defined as more than $2 \mathrm{~mm}$ of


Fig. 1. Technique of measuring ABL. Arrowed lines represent the subchondral length; dashed line represents the posterior vertebral line. The numeric formula used to determine the percentage of $A B L$ was: $A B L=(a-b) / a \times 100$. (A) Immediate postoperative $X$-ray. (B) Follow-up Xray. $A B L$, anterior bone loss.



Fig. 2. Illustration of the anterior implant exposure (defined as b $>2$ $\mathrm{mm}$ ) and implant subsidence (defined as either: $x>5^{\circ}$ or $a-d>2 \mathrm{~mm}$ ).

anterior implant exposure or endplate collapse and implant subsidence was defined as more than $5^{\circ}$ of kyphotic change in the implant position relative to the posterior vertebral line or more than $2 \mathrm{~mm}$ of height loss of the implant relative to the anterior or posterior vertebral body height of the immediate postoperative X-ray (Fig. 2).

Each endplate was analyzed in isolation, such that each implant had two endplates assessed (upper being cranial and lower being caudal of the implant). Endplates that were not clearly visible were excluded. To ensure that no markedly malpositioned implants were studied, endplates that had implants that were positioned more anteriorly than $3 \mathrm{~mm}$ from the posterior vertebral line on the lateral $\mathrm{X}$-ray or had more than $3 \mathrm{~mm}$ of central asymmetry on the AP X-ray (defined as the distance from the midpoint 
of the implant compared to the midpoint of the superior endplate) were excluded. Comparative radiographs were studied at 6 weeks, 3, 6, 9, 12, 18, and 24 months, and annually thereafter, with a minimum follow-up of 5 years (maximum, 8 years). For each time interval, ABL was assessed. If the patient failed to have a radiograph taken at the intended time interval, the ABL for that time interval was not recorded, unless there was no difference between the previous and subsequent radiographs, in which case the ABL was recorded as the same amount as in the adjacent time periods.

ABL was classified into three groups: mild $(\leq 5 \%)$, moderate $(6 \%-10 \%)$, and severe $(>10 \%)$. The radiographic natural history was studied. In addition, Visual Analog Scale (VAS) neck and arm pain scores were obtained preoperatively, 3 months postoperatively, and 5 years postoperatively. Neck Disability Index (NDI) scores were obtained at 5 years. Pain and functional outcome scores were compared among the groups.

Statistical results are presented as mean values (and/or percentages) with standard deviations. Chi-square test of independence was used to identify relationships of age (5year age brackets), sex, or operated level with ABL degree. At each observation period, the VAS and NDI results were compared among the different ABL-degree groups, using one-way analysis of variance. Where these analyses indicated significant associations, pairwise comparisons among the ABL groups were undertaken. Statistical significance was defined as a two-tailed $p$-value of less than 0.05 .

\section{Results}

Of the 146 patients that were analyzed, complete radiological assessment was available for 114 patients and 156 CDAs (average age, 45.3 years; maximum, 65 years; minimum, 28 years; $57 \%$ females). This comprised 56 with Bryan (Medtronic Sofamor Danek, 32 patients), 44 with Discocerv (Alphatech Spine Inc., 38 patients), and 56 with Baguera-C CDAs (Spineart, 44 patients). Of these, 78 patients had single-level, 30 had double-level, and six had triple-level CDAs. Thirteen patients had a hybrid procedure with concomitant fusion at the time of CDA. In all cases, the posterior longitudinal ligament was resected, whereas the uncinate processes were not.

From the 156 CDAs, 309 endplates were assessed, including 55 upper and 56 lower Bryan (Medtronic Sofamor Danek), 44 upper and 44 lower Discocerv (Alphatech Spine Inc.), and 54 upper and 56 lower Baguera-C (Spineart) CDAs. The most common level operated on was $\mathrm{C} 5 / 6$ (range, $\mathrm{C} 3 / 4-\mathrm{C} 6 / 7$ ).

ABL was identified in $57.1 \%$ of CDAs (Table 1) and had no identified correlation with age, sex, or operated level $(p>0.05)$. Severe ABL was only identified in the Discocerv CDA (11.4\% of Discocerv CDAs, Alphatech Spine Inc.) and included one single-level, double-level, and triple-level CDA each. Of the 309 endplates assessed, $48.5 \%$ were affected by ABL (Table 2).

Mild and moderate ABL predominantly affected the upper endplate (56.8\% and $57.9 \%$, respectively). Severe ABL

Table 1. Maximal degree of anterior bone loss identified per cervical disc arthroplasty

\begin{tabular}{lccccc} 
Implant & None & Mild & Moderate & Severe & Total \\
All implants & $67(42.9)$ & $71(45.5)$ & $13(8.3)$ & $7(3.2)$ & 0 \\
Bryan & $24(42.9)$ & $25(44.7)$ & $7(12.5)$ & $5(11.4)$ & 56 \\
Discocerv & $23(52.3)$ & $12(27.3)$ & $2(3.6)$ & 0 & 44 \\
Baguera C & $20(35.7)$ & $34(60.7)$ & 56 & \\
\hline
\end{tabular}

Values are presented as number (\%). The implants were from the following companies: Bryan disc (Medtronic Sofamor Danek, Memphis, TN, USA), the Discocerv (Alphatech Spine Inc., Carlsbad, CA, USA), and the Baguera C (Spineart, Geneva, Switzerland).

Table 2. Maximal degree of anterior bone loss per endplate

\begin{tabular}{lccccc} 
& None & Mild & Moderate & Severe & Total \\
Upper & $69(45.1)$ & $71(46.4)$ & $11(7.2)$ & $2(1.3)$ & 153 \\
Lower & $90(57.7)$ & $54(34.6)$ & $8(5.1)$ & $4(2.6)$ & 156 \\
Total & $159(51.5)$ & $125(40.5)$ & $19(6.1)$ & $6(1.9)$ & 309 \\
\hline
\end{tabular}

Values are presented as number (\%). 




Fig. 3. Change in the percentage of $A B L$ over time for mild, moderate, and severe $A B L$ groups. $A B L$, anterior bone loss.

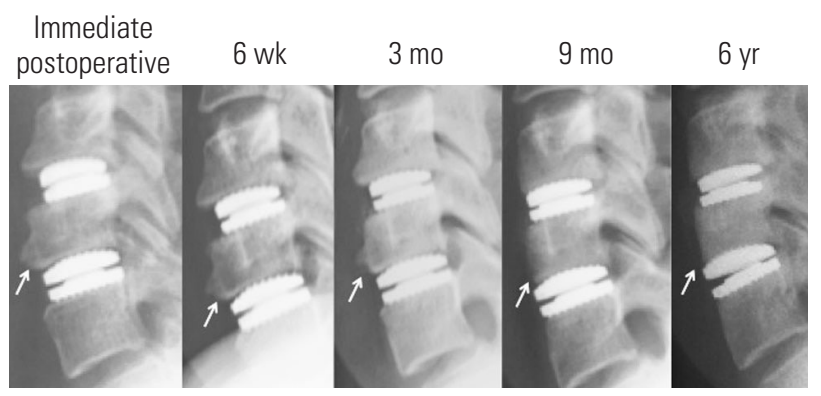

Fig. 4. Radiographs of the lateral cervical spine of a representative case with multi-level cervical disc arthroplasties showing the natural history of mild anterior bone loss (arrow).

predominantly affected the lower endplate (66.7\%), especially when endplate collapse occurred (75\%).

The natural history of ABL showed that this phenomenon typically commenced within 3 months of the index operation and followed a benign course, with improvement in bone stock after the initial bone loss (Fig. 3). Throughout the study period, all implants remained stable with no implants revised or repeat operations recorded.

Most ABL identified was mild (45.5\% of CDAs, $40.5 \%$ of endplates). It typically appeared as blunting of the anterior vertebra commencing within the first 3 months and the display of stable radiographic features after 6-9 months (Fig. 4). No implant subsidence or implant uncoverage occurred.

Moderate ABL was identified in $8.3 \%$ of CDAs (6.1\% of endplates). It typically resulted in anterior CDA uncoverage (61.5\%), but a stable radiographic appearance after

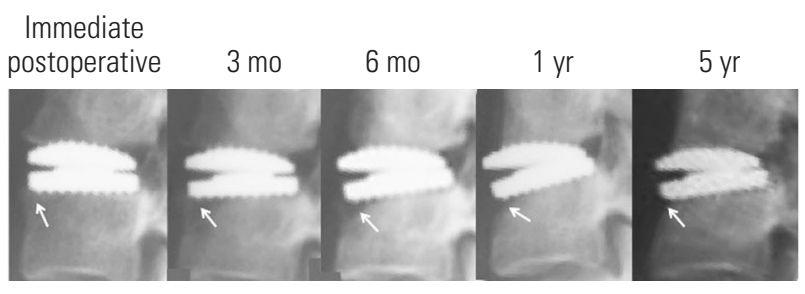

Fig. 5. Radiographs of the lateral cervical spine of a representative case showing the natural history of moderate $\mathrm{ABL}$ in the upper endplate and severe $A B L$ with collapse in the lower endplate (arrow). $A B L$, anterior bone loss.
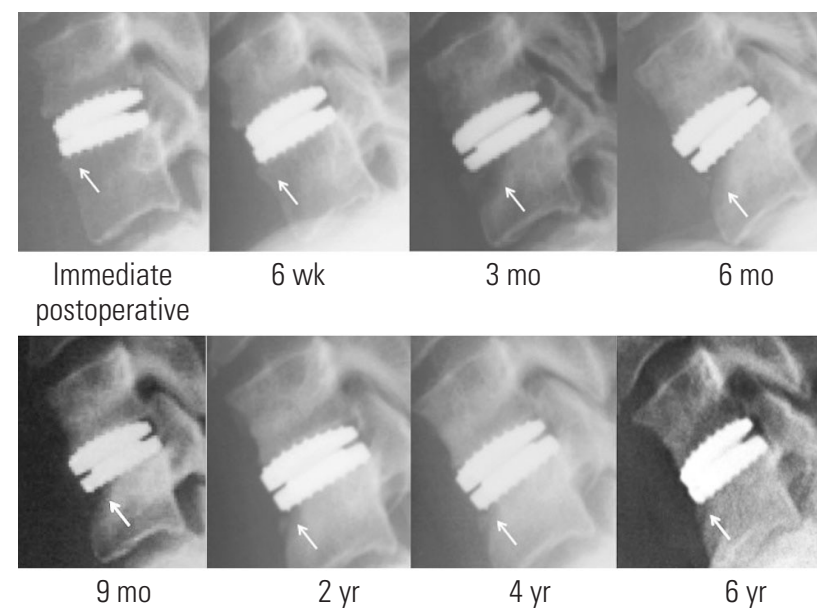

Fig. 6. Severe anterior bone loss with minimal implant collapse and initial bone loss reconstitution (arrow).

9-12 months (Fig. 5). No implant subsidence occurred.

Severe ABL was rare (3.2\% of CDAs, $1.9 \%$ of endplates). It typically commenced within the first 3 months, with progression during the first year, but with stable or improving radiographic features after this period (Fig. 5).

Severe ABL always caused anterior uncoverage of the $\mathrm{CDA}$ and compromised endplate stability causing implant subsidence in $66.7 \%$ of cases. Endplate collapse and implant subsidence were seen to affect the anterior portion of the vertebra more than the posterior portion, even when the entire endplate was affected. However, the bone typically healed in the collapsed position to provide a stable implant with maintenance of prosthetic function or subsequent fusion (Fig. 6).

Occasionally, despite severe ABL, the implant did not subside or did so only minimally $\left(<20^{\circ}\right.$ or $\left.4 \mathrm{~mm}\right)$. In these cases, the bone reconstituted beneath the implant over a number of years along with the maintenance of implant stability (Fig. 6).

Table 3 illustrates the pain and functional outcome 
Table 3. Comparative pain and functional outcome scores according to the degree of $\operatorname{ABL}\left({ }^{\circ}\right)$

\begin{tabular}{|c|c|c|c|c|c|c|c|}
\hline \multirow{2}{*}{ Degree of $A B L\left({ }^{\circ}\right)$} & \multicolumn{3}{|c|}{ VAS neck } & \multicolumn{3}{|c|}{ VAS arm } & \multirow{2}{*}{$\frac{\text { Neck Disability Index }}{5 \text { yr postop }}$} \\
\hline & Preop & 3 mo postop & 5 yr postop & Preop & 3 mo postop & 5 yr postop & \\
\hline None & 5.7 & 2.4 & 2.2 & 6.2 & 1.7 & 1.6 & 18.9 \\
\hline Mild & 6.0 & 1.2 & 1.1 & 7.0 & 1.1 & 1.1 & 11.2 \\
\hline Moderate & 6.2 & 0.8 & 1.7 & 7.4 & 0.7 & 1.3 & 10.1 \\
\hline Severe & 5.9 & 3.0 & 2.6 & 8.0 & 1.8 & 3.1 & 9.0 \\
\hline$p$-value & 0.930 & 0.286 & 0.081 & 0.600 & 0.489 & 0.577 & 0.094 \\
\hline
\end{tabular}

ABL, anterior bone loss; VAS, Visual Analog Scale; Preop, preoperative; Postop, postoperative.

scores according to ABL degree and follow-up duration. There was no significant association between VAS scores or NDI and ABL degree. Within the timeframe of this study, there was no evidence of progressive disease, overall, or when each category of ABL was analyzed independently.

\section{Discussion}

$\mathrm{ABL}$ is a common condition (57.1\% of CDA). Its natural history involves non-progressive early bone loss commencing within 3 months of the index operation, which favors early bone remodeling or an osteolytic insult inflicted during the procedure. Notably, the natural history is not consistent with wear debris or low-grade infection, which would more likely produce progressive bone loss.

Heo et al. [26] propose that the most likely cause of this phenomenon is stress shielding from the implant. However, implant-related stress shielding occurs when a portion of the bone is no longer loaded and thus resorbs. This phenomenon, at least in large joints, progressively occurs over several years rather than the first 3 months [27-29]. Furthermore, a rebound of bone formation does not occur, as only bone that is not loaded is initially resorbed. In our series, we found early bone loss with subsequent reconstitution. This would suggest that stress shielding from the implant is unlikely. Furthermore, we included multiple implant types to ensure a diverse modulus of elasticity and biocompatibility and found this phenomenon occurring in all implant types studied. Therefore, we believe that the cause is not likely to be implant-related stress shielding.

Rather, we believe that the bone resorption occurs from resection of the anterior longitudinal ligament, which no longer tractions the anterior vertebral beak and is therefore likely to account for the ABL encountered in mild and moderate cases. An alternative cause in these cases

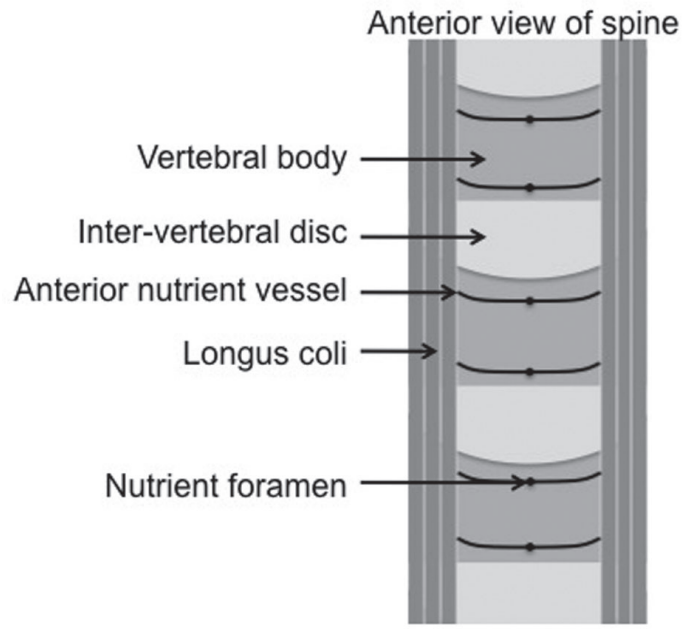

Fig. 7. Illustration of the anterior view of the spine with the proposed nutrient vessels of the anterior vertebrae.

could be a direct osteolytic insult, such as heat necrosis from cautery, inflicted on the anterior vertebra during the exposure of the intervertebral disc.

Owing to the size and rate of $\mathrm{ABL}$ in severe cases, we believe that the cause is more likely related to a surgical insult causing avascular necrosis (AVN) of the anterior portion of the endplate. It has been well described that the vertebral body obtains most of its vascular supply from a branch of the posterior arterial vertebral plexus that penetrates the vertebral body through the basivertebral foramen [30]. However, this is not the sole supply of the vertebra. An additional vessel, commencing within the same posterior plexus, wraps around the vertebra to terminate in a small anterior nutrient artery [30]. Significant anatomical variations occur and the degree of anterior vertebra supplied by this vessel is not known. However, it is likely that, in some patients, this vessel greatly contributes to the vascularity of the anterior vertebral body.

To date, the exact insult causing AVN remains un- 
known. Intra-operatively, a lateral vessel is often encountered and coagulated at the margin of the longus coli (Fig. 7). However, this is the vessel described above and its damage may contribute to AVN of the anterior vertebra in a patient with predominant anterior vascular supply. Similarly, midline dissection and exposure with the insertion of traction pins may directly injure the anterior nutrient artery as it penetrates the vertebra, resulting in the same effect. Alternative causes of AVN include direct endplate damage during endplate preparation or endplate hyperpressure from the implant.

We classified ABL according to the percentage of subchondral bone loss occurring relative to the level at the initial postoperative X-ray (Fig. 1). In some centers, the anterior beak is resected routinely during the surgical procedure; however, at our institution, beak resection is not performed. Thus, our classification includes regression of the beak as is seen in mild cases.

We utilized a percentage-based classification system of ABL to accurately define the extent of this phenomenon. Clearly, an anteriorly placed implant, or oversized implant, with the same ABL degree will have greater implant exposure than a more centrally positioned, adequately sized one (Fig. 8). Therefore, our classification system, which utilizes the percentage of ABL rather than the degree of implant exposure, accounts for moderate variations in the initial implant position. However, it should be recognized that our study excluded markedly malpositioned implants. Thus, it is possible that a poorly positioned implant may subside with less ABL than described in our classification system. In view of this, further analysis of the percentage


Fig. 8. Two cases of moderate $A B L$, with $(\mathbf{A})$ being an adequately positioned and sized implant and (B) being a comparatively anteriorly positioned and oversized implant. Note the implant exposure in (B). However, the percentage of $A B L$ was same for both the cases. $A B L$, anterior bone loss. of implant support necessary to prevent implant collapse is necessary.

In our proposed classification system (Table 4), mild cases are described as those with $\leq 5 \% \mathrm{ABL}$ and typically involve blunting of the anterior vertebral beak. This occurs more commonly than no bone loss $(45.5 \%$ versus 42.9\%) and does not expose or compromise the implant. The authors believe that mild ABL is of no concern and does not warrant continued monitoring.

Moderate $\mathrm{ABL}$ is described as $\mathrm{ABL}$ of $6 \%-10 \%$ and is similar to mild cases, but may expose the implant. However, the endplate is not compromised and the implant remains stable; thus, we believe that continued monitoring is not necessary.

Severe $\mathrm{ABL}$ is described as that of $>10 \%$, is likely caused by AVN of the anterior subchondral bone, and the bone loss always extends beyond the anterior portion of the implant. This ABL degree may compromise the biomechanical integrity of the endplate and risk implant subsidence. If subchondral collapse occurs, the bone typically heals in the collapsed position and may auto-fuse. If collapse does not occur, the initial bone defect will typically reconstitute partially or completely over a number of years. We therefore advocate close monitoring in severe cases without implant collapse until radiographic improvement or a stable state is attained (usually 1 year). We are currently monitoring severe cases with implant collapse to ensure the integrity of the adjacent levels. To date, with a minimum follow-up of 5 years, we have not encountered adjacent segment disease in any of these cases.

Irrespective of the ABL degree identified, it is important to note that continued progression of $\mathrm{ABL}$ did not occur beyond the first year. This is consistent with the results reported by Heo et al. [26]. Thus, we propose that ABL is a non-progressive phenomenon and, provided that it follows this typical natural history, the implant can be observed and the patient treated non-operatively.

In addition, the range of implants studied in this review and those reported in previous publications would suggest that $\mathrm{ABL}$ is not implant-specific, but rather techniquespecific $[22,24-26]$. We would therefore agree with previous authors who have excluded the anterior flange of the Bryan disc as the cause of ABL in this prosthesis [26]. We would also advocate further research into the surgical risk factors contributing to this phenomenon.

We also found no correlation between ABL degree and 3-month VAS scores. Heo et al. [26] found that, despite all 
Table 4. Classification of anterior bone loss

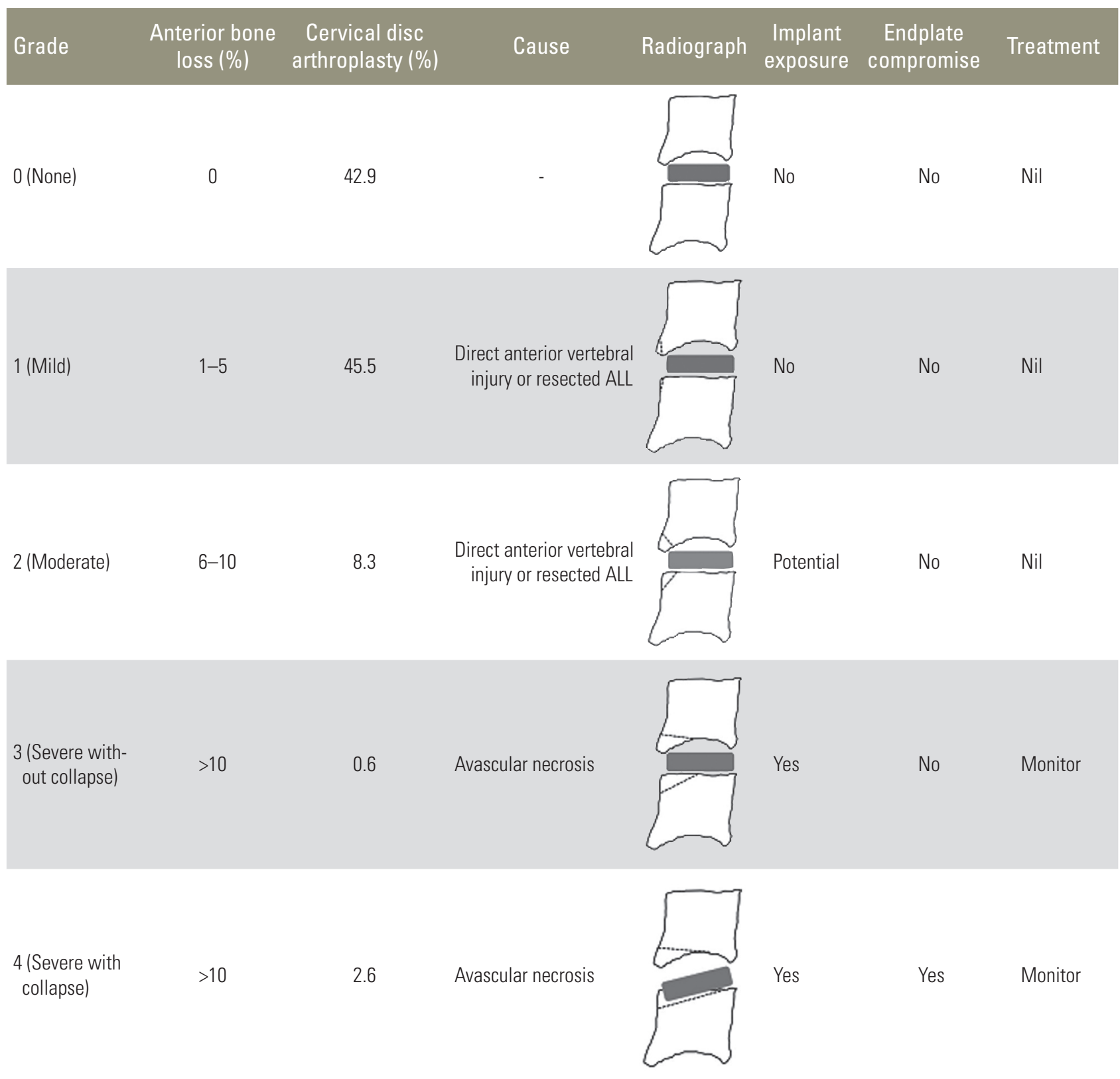

ALL, anterior longitudinal ligament.

patients improving from their preoperative state, similar to our patients, there were significantly lower functional scores and higher pain scores within the first year for patients with ABL causing exposure of the prosthesis. We analyzed VAS scores at 3 months because all patients with ABL had radiological evidence of this phenomenon at this time point. However, our study is limited by a lack of additional pain and functional scores during the first year.

Heo et al. [26] found that the difference in early functional scores with those who develop ABL improved and that there was no difference between the groups after the first year. This is consistent with our radiographic results, which suggest that ABL occurs at an early stage and follows a non-progressive course with stable radiographic features beyond the first year. This is also supported by our 5-year VAS and NDI scores showing no significant differences between the groups.

Reassuringly, within the timeframe of this study, none of the patients required repeated surgical intervention. Thus, the clinical effect of this phenomenon remains un- 
clear. However, clinicians can be reassured about its benign nature and mid-term results.

A limitation of this study is the analysis of only nonkeeled implants, which were specifically chosen to optimize the radiological assessment, which is otherwise obscured by an artifact from the keel. Additionally, patient's medical comorbidities did not correlate with the activity level. Similarly, the degree of surgical insult to the anterior vertebra, the use of distraction pins, and the amount of pre-vertebral coagulation were unknown. In addition, markedly malpositioned implants were not included in the study, and therefore the endplate collapse and implant subsidence rates only reflect the results in adequately positioned implants. Lastly, despite the large number of CDAs reported, the numbers of each implant type were low and precluded accurate assessment of the risk among the implants. Despite our study only illustrating severe ABL in the Discocerv CDA, our institution has managed severe $\mathrm{ABL}$ affecting multiple different prostheses, but these were not included in the current study due to our exclusion criteria, particularly external referrals from other centers and limited radiographic follow-up.

Owing to these limitations, our proposed causes of ABL need to be interpreted with caution. Further research is warranted to account for the shortcomings of this study. We would also encourage an assessment of ABL in anterior cervical discectomy and fusion procedures to further prove that $A B L$ occurs due to the surgical technique used rather than it being an implant-specific phenomenon.

\section{Conclusions}

This study demonstrates that ABL is a common condition (57.1\%). It occurs at an early stage (within 3 months) and follows a non-progressive natural history, typically with stable radiographic features after the first year. $\mathrm{ABL}$ is mostly observed to be mild, but severe ABL occurs in approximately $3 \%$ of CDAs. It does not affect the patient's clinical outcome or the requirement for revision surgery. Surgeons should be aware of this phenomenon and treat patients expectantly.

\section{Conflict of Interest}

No potential conflict of interest relevant to this article was reported.

\section{Acknowledgments}

The researchers are grateful to the Glynny Kieser for her editorial input.

\section{Author Contributions}

Kieser DC: study design, data acquisition and analysis, and drafting of the manuscript; Cawley DT: X-ray review, data analysis, drafting of the manuscript, and critical appraisal; Fujishiro T: X-ray review, data analysis, and critical appraisal; Tavolaro C: critical appraisal; Mazas S: data acquisition, analysis, and critical appraisal; Boissiere L: critical appraisal and study oversight; Obeid I: critical appraisal and study oversight; Pointillart V: critical appraisal and study oversight; Vital JM: critical appraisal and study oversight; and Gille O: study design, critical appraisal, and study oversight.

\section{References}

1. Reitz H, Joubert MJ. Intractable headache and cervico-brachialgia treated by complete replacement of cervical intervertebral discs with a metal prosthesis. S Afr Med J 1964;38:881-4.

2. Heller JG, Sasso RC, Papadopoulos SM, et al. Comparison of BRYAN cervical disc arthroplasty with anterior cervical decompression and fusion: clinical and radiographic results of a randomized, controlled, clinical trial. Spine (Phila Pa 1976) 2009;34:101-7.

3. Coric D, Kim PK, Clemente JD, Boltes MO, Nussbaum $\mathrm{M}$, James S. Prospective randomized study of cervical arthroplasty and anterior cervical discectomy and fusion with long-term follow-up: results in 74 patients from a single site. J Neurosurg Spine 2013;18:36-42.

4. Traynelis VC, Arnold PM, Fourney DR, Bransford RJ, Fischer DJ, Skelly AC. Alternative procedures for the treatment of cervical spondylotic myelopathy: arthroplasty, oblique corpectomy, skip laminectomy: evaluation of comparative effectiveness and safety. Spine (Phila Pa 1976) 2013;38(22 Suppl 1):S210-31.

5. Burkus JK, Traynelis VC, Haid RW Jr, Mummaneni PV. Clinical and radiographic analysis of an artificial cervical disc: 7-year follow-up from the Prestige prospective randomized controlled clinical trial: clinical article. J Neurosurg Spine 2014;21:516-28.

6. Radcliff K, Coric D, Albert T. Five-year clinical results of cervical total disc replacement compared 
with anterior discectomy and fusion for treatment of 2-level symptomatic degenerative disc disease: a prospective, randomized, controlled, multicenter investigational device exemption clinical trial. J Neurosurg Spine 2016;25:213-24.

7. Mummaneni PV, Amin BY, Wu JC, Brodt ED, Dettori JR, Sasso RC. Cervical artificial disc replacement versus fusion in the cervical spine: a systematic review comparing long-term follow-up results from two FDA trials. Evid Based Spine Care J 2012;3(S1):59-66.

8. Wu JC, Hsieh PC, Mummaneni PV, Wang MY. Spinal motion preservation surgery. Biomed Res Int 2015;2015:372502.

9. Denaro V, Papalia R, Denaro L, Di Martino A, Maffulli N. Cervical spinal disc replacement. J Bone Joint Surg Br 2009;91:713-9.

10. Skovrlj B, Lee DH, Caridi JM, Cho SK. Reoperations following cervical disc replacement. Asian Spine J 2015;9:471-82.

11. Morrey BF, Bryan RS. Complications of total elbow arthroplasty. Clin Orthop Relat Res 1982;(170):204-12.

12. Klimkiewicz JJ, Iannotti JP, Rubash HE, Shanbhag AS. Aseptic loosening of the humeral component in total shoulder arthroplasty. J Shoulder Elbow Surg 1998;7:422-6.

13. Orishimo KF, Claus AM, Sychterz CJ, Engh CA. Relationship between polyethylene wear and osteolysis in hips with a second-generation porous-coated cementless cup after seven years of follow-up. J Bone Joint Surg Am 2003;85-A:1095-9.

14. Elhassan B, Ozbaydar M, Higgins LD, Warner JJ. Glenoid reconstruction in revision shoulder arthroplasty. Clin Orthop Relat Res 2008;466:599-607.

15. Boyle C, Kim IY. Comparison of different hip prosthesis shapes considering micro-level bone remodeling and stress-shielding criteria using three-dimensional design space topology optimization. J Biomech 2011;44:1722-8.

16. Au AG, James Raso V, Liggins AB, Amirfazli A. Contribution of loading conditions and material properties to stress shielding near the tibial component of total knee replacements. J Biomech 2007;40:1410-6.

17. Gallo J, Goodman SB, Konttinen YT, Wimmer MA, Holinka M. Osteolysis around total knee arthroplasty: a review of pathogenetic mechanisms. Acta Biomater 2013;9:8046-58.

18. Demetracopoulos CA, Halloran JP, Maloof P, Adams
SB Jr, Parekh SG. Total ankle arthroplasty in endstage ankle arthritis. Curr Rev Musculoskelet Med 2013;6:279-84.

19. Chen CM, Tsai WC, Lin SC, Tseng CS. Effects of stemmed and nonstemmed hip replacement on stress distribution of proximal femur and implant. BMC Musculoskelet Disord 2014;15:312.

20. Panegrossi G, Ceretti M, Papalia M, Casella F, Favetti F, Falez F. Bone loss management in total knee revision surgery. Int Orthop 2014;38:419-27.

21. Vasso M, Beaufils P, Cerciello S, Schiavone Panni A. Bone loss following knee arthroplasty: potential treatment options. Arch Orthop Trauma Surg 2014;134:543-53.

22. Kim SH, Chung YS, Ropper AE, et al. Bone loss of the superior adjacent vertebral body immediately posterior to the anterior flange of Bryan cervical disc. Eur Spine J 2015;24:2872-9.

23. Fraser JF, Werner S, Jacofsky DJ. Wear and loosening in total knee arthroplasty: a quick review. J Knee Surg 2015;28:139-44.

24. Tumialán LM, Gluf WM. Progressive vertebral body osteolysis after cervical disc arthroplasty. Spine (Phila Pa 1976) 2011;36:E973-8.

25. Veruva SY, Lanman TH, Hanzlik JA, Kurtz SM, Steinbeck MJ. Rare complications of osteolysis and periprosthetic tissue reactions after hybrid and non-hybrid total disc replacement. Eur Spine J 2015;24 Suppl 4:S494-501.

26. Heo DH, Lee DC, Oh JY, Park CK. Bone loss of vertebral bodies at the operative segment after cervical arthroplasty: a potential complication? Neurosurg Focus 2017;42:E7.

27. Engh CA, Massin P. Cementless total hip arthroplasty using the anatomic medullary locking stem: results using a survivorship analysis. Clin Orthop Relat Res 1989;(249):141-58.

28. Kilgus DJ, Shimaoka EE, Tipton JS, Eberle RW. Dualenergy X-ray absorptiometry measurement of bone mineral density around porous-coated cementless femoral implants: methods and preliminary results. J Bone Joint Surg Br 1993;75:279-87.

29. Yamada H, Yoshihara Y, Henmi O, et al. Cementless total hip replacement: past, present, and future. J Orthop Sci 2009;14:228-41.

30. Harris RS, Jones DM. The arterial supply to the adult cervical vertebral bodies. J Bone Joint Surg Br 1956;38-B:922-7. 